\title{
A role for kisspeptins in pregnancy: facts and speculations
}

\author{
Rebecca M Reynolds ${ }^{1}$, James J Logie ${ }^{2}$, Antonia K Roseweir ${ }^{3}$, Angus J McKnight ${ }^{2}$ \\ and Robert P Millar ${ }^{3,4}$ \\ ${ }^{1}$ Endocrinology Unit, Centre for Cardiovascular Sciences, ${ }^{2}$ Jennifer Brown Research Laboratory and ${ }^{3}$ MRC Human \\ Reproductive Sciences Unit, Queen's Medical Research Institute, University of Edinburgh, 47 Little France Crescent, \\ Edinburgh EH16 4TJ, UK and ${ }^{4}$ Receptor Biology Group, Division of Medical Biochemistry, University of Cape Town, \\ Cape Town 7925, South Africa
}

Correspondence should be addressed to R M Reynolds; Email: r.reynolds@ed.ac.uk

\begin{abstract}
Kisspeptin is a neuropeptide that was originally discovered in 1996 from a metastasis tumour suppressor gene, KISS1 and was appropriately named metastin. More recently, the discovery of inactivating mutations in the receptor for kisspeptin, a $\mathrm{G}$ protein-coupled receptor, GPR54 (KISS1R), have been shown to result in a failure to progress through puberty in man. These findings have led to the kisspeptin/KISS1R system being described as an essential gatekeeper of reproductive function. Recent studies have suggested additional roles of kisspeptin, other than in the central control of the gonadotropic axis including placentation and pregnancy, energy homeostasis and cardiovascular function. Therefore, kisspeptin-KISS1R signalling potentially plays diverse roles in human physiology. Here, we review the literature regarding the role and physiological significance of kisspeptin in pregnancy and highlight some of the key questions that require addressing.

Reproduction (2009) 138 1-7
\end{abstract}

\section{Introduction}

Kisspeptin is a neuropeptide that was originally discovered in 1996 from a metastasis tumour suppressor gene, KISS1 (Lee et al. 1996) and was appropriately named metastin. More recently, the discovery of inactivating mutations in the receptor for kisspeptin, a G-protein-coupled receptor, KISS1R, have been shown to result in a failure to progress through puberty in man (de Roux et al. 2003, Seminara et al. 2003, Lanfranco et al. 2005, Semple et al. 2005). These findings have led to the kisspeptin/KISS1R system being described as an essential gatekeeper of reproductive function (Seminara et al. 2003). Recent studies have suggested additional roles of kisspeptin, other than in the central control of the gonadotrophic axis including placentation and pregnancy, energy homeostasis and cardiovascular function (Bilban et al. 2004, Tena-Sempere 2006, Crown et al. 2007, Hiden et al. 2007, Mead et al. 2007b). Therefore, kisspeptin-KISS1R signalling potentially plays diverse roles in human physiology. Here, we review the literature regarding the role and physiological significance of kisspeptin in pregnancy and highlight some of the key questions that require addressing.

\section{Kisspeptins and KISS1R}

\section{Discovery and nomenclature}

Kisspeptins comprise a family of peptides derived from the primary translation product of the KISS1 gene, localized to chromosome 1, which were identified more than a decade ago (Lee et al. 1996). These peptides were discovered as the result of a systematic bioinformatics search for processed peptides encoded by the human genome (Ohtaki et al. 2001), and simultaneously by the isolation of a biological activity from human placenta and its identification by mass spectrometry (Kotani et al. 2001). Proteolytic processing of the full-length 145 amino acid kisspeptin protein results in shorter fragments of the carboxyl (C)-terminus region of the molecule with 54 (KP-54; previously designated metastin), 14 (KP14), 13 (KP-13) or 10 (KP-10) amino acids (Kotani et al. 2001, Ohtaki et al. 2001). Initially, the largest cleavage product, KP-54 was identified for its ability to suppress the metastatic potential of malignant melanoma cells (Lee et al. 1996, Lee \& Welch 1997) and it was therefore termed 'metastin' (Ohtaki et al. 2001). Interestingly, the naming of the gene KISS1 and its product, kisspeptin (aka metastin), was made by the 
team of scientists who discovered the gene in the town of Hershey, Pennsylvania, famous for its chocolate 'kisses', with inclusion of the terminology 'SS' also indicating a suppressor sequence. The term 'kisspeptins' is now widely employed to collectively describe this family of peptides that show an Arg-Phe- $\mathrm{NH}_{2}$ motif at the C-terminus, characteristic of the extensive RF-amide peptide superfamily (Roa et al. 2008).

\section{Intracellular signalling}

The mechanism(s) of action of kisspeptins are only partially elaborated. Kisspeptins are endogenous ligands for a G-protein-coupled receptor named GPR54 (in rat), hOT7T175, AXOR12 (the human homologues), or alternatively, KISS1R (Lee et al. 1999, Muir et al. 2001). KISS1R was originally cloned from rat brain tissue as an orphan receptor with a sequence similar (28-39\% protein homology) to the galanin receptors (Lee et al. 1999) although it is unresponsive to galanin ligands. In 2001, kisspeptins were shown to be the endogenous ligands for KISS1R (Kotani et al. 2001, Muir et al. 2001, Ohtaki et al. 2001). All kisspeptins are able to bind KISS1R, with KP-10 having maximal activity at the receptor level (Kotani et al. 2001). Indeed, KP-10 is highly conserved between human, sheep, mouse and rat, with only one amino acid difference in the sequence between species. The major intracellular signalling system recruited by KISS1R is the Gq pathway, which activates phospholipase $\mathrm{C}$ to hydrolyse phosphatidylinositol bisphosphate to inositol trisphosphate and diacyl glycerol, which mobilize intracellular $\mathrm{Ca}^{2+}$ mobilization and activate protein kinase $\mathrm{C}$ respectively (Muir et al. 2001, Becker et al. 2005). This subsequently causes downstream activation of MAPK3/1 and MAPK14 MAP kinases in a variety of cell types including KISS1Rtransfected Chinese hamster ovary $(\mathrm{CHO})$ cells (Kotani et al. 2001) and trophoblast cells (Bilban et al. 2004, Castellano et al. 2006).

Kisspeptin has also been shown to signal to a variety of factors involved in cell migration, which have been hypothesized to be important in both trophoblast and metastasis inhibition. For example, kisspeptin can induce focal adhesion and stress fibre formation (Kotani et al. 2001, Ohtaki et al. 2001). Kisspeptin can also phosphorylate focal adhesion kinase and paxillin, the intracellular signals needed for these events, which may associate with integrins to inhibit migration (Ohtaki et al. 2001). Kisspeptin has also been shown to diminish matrix metalloprotease (MMP) 9 expression by reduced NFKB binding to the MMP9 promoter, to cause an inhibition of cell migration (Yan et al. 2001). This may also prove to be important in placentation but additional work will be necessary to determine which factors are involved in the activation of the NFKB pathway by KISS1R.
Finally, it has been suggested that kisspeptin may suppress metastasis by induction of apoptosis in cells since metastatic spread is dependent on cell growth (Harms et al. 2003), but there have been conflicting reports in the literature. Culturing recombinant $\mathrm{CHO}$ cells with $1 \mu \mathrm{M} \mathrm{KP}-10$ resulted in a strong antiproliferative effect, while no evidence of apoptosis was detected (concentration used not disclosed; Kotani et al. 2001). By contrast, in a more recent study using human mammary carcinoma cells and a cDNA microarray, stimulation of KISS1R by $500 \mathrm{nM} \mathrm{KP-10}$ caused upregulation of several genes involved in cell cycle progression (including CDKN1A, GADD45A, GADD45B, and HIF1A-responsive DDIT4), cell cycle arrest and apoptosis (Becker et al. 2005).

\section{Tissue distribution}

Tissue distribution of KISS1R and KISS1 often coincides. Distribution has been best described in the rodent where expression of both receptor and ligand are the highest in placenta, with additional wide distribution throughout the $\mathrm{CN}$ (the highest levels in hypothalamus and pituitary but also in cerebellum, cortex and brainstem; Lee et al. 1996, Kotani et al. 2001, Muir et al. 2001). There are also some reports of variable expression in rodent adipose tissue, pancreas, liver, small intestine, peripheral blood lymphocytes, testes, lymph nodes, and in human aorta, coronary artery and umbilical vein, although the cellular distribution is not always well described (Muir et al. 2001, Ohtaki et al. 2001, Hauge-Evans et al. 2006, Mead et al. 2007a). Moreover, the specificity of antiserum used in some of these studies has yet to be fully confirmed. This is crucial in view of the large number of peptides with the RF.NH ${ }_{2}$ motif at their carboxyl termini. The cellular distribution in the placenta will be described in more detail below.

\section{Kisspeptin and reproduction \\ Puberty}

The connection between the kisspeptin/KISS1R system and pubertal development was revealed in 2003 when two groups independently reported the presence of inactivating mutations of KISS1R in patients with hypogonadotrophic hypogonadism (de Roux et al. 2003, Seminara et al. 2003), a condition characterized by the absence of sexual maturation and decreased levels of sex hormones and gonadotrophins. Numerous and extensive studies provide cogent arguments for a crucial role for kisspeptin in development, puberty and adult function of the hypothalamic-pituitary-gonadal axis (see reviews by Colledge 2004, Crown et al. 2007, Roa et al. 2008). The link between kisspeptin activation and onset of puberty was confirmed following the description of the 
phenotype of Kiss $1 r$-knockout mice which closely paralleled that of human hypogonadotrophic hypogonadism (Funes et al. 2003, Seminara et al. 2003). Mice lacking the KISS1R receptor failed to undergo puberty and mutant males were sterile with very small genitalia and lacked secondary sexual characteristics (Funes et al. 2003, Seminara et al. 2003). Similarly, mutant female mice also failed to undergo sexual maturation; the uterine horns from mutants were thread-like and the ovaries significantly smaller than normal. In addition, the ovaries contained primary and secondary follicles but large antral (Graafian) follicles or corpora lutea were never found. The phenotype of Kiss 1 r-null mice was consistent with a lack of sex steroid production and serum testosterone and oestradiol levels were lower than normal in these animals (Seminara et al. 2003). It has also been reported that mice lacking the Kiss 1 gene exhibited abnormal timing of puberty (d'Anglemont de Tassigny et al. 2007, Lapatto et al. 2007), although their reproductive phenotypes were not as severe as the Kiss $1 r$-knockout mice. These animals also have impaired sexual maturation, low gonadotrophin levels and abnormal gametogenesis, but the phenotype of Kiss1knockout mice appears to be more variable, with some animals being less severely affected, and indeed, some females having larger gonadal weight and persistent vaginal cornification (Lapatto et al. 2007). This may suggest different thresholds for sexual maturation or that other RF. $\mathrm{NH}_{2}$ peptides may be able to substitute for kisspeptins.

In support of a role for kisspeptin as a gatekeeper of puberty, a gain-of-function mutation that activates KISS1R signalling has recently been described in an 8-year old girl who presented with idiopathic central precocious (premature) puberty (Teles et al. 2008). In vitro studies demonstrated that the substitution of proline for arginine at amino acid 386 (Arg386Pro) leads to prolonged activation of intracellular signalling pathways in response to kisspeptin (Teles et al. 2008). Consequently, KISS1R agonists have therapeutic potential in initiating puberty in cases of pubertal delay and kisspeptin antagonists or desensitization with agonists may find application in precocious puberty.

\section{Pregnancy and placenta}

Circulating kisspeptin levels are low in males and nonpregnant females $(<2 \mathrm{pmol} / \mathrm{l})$ but dramatically increase in pregnancy (Horikoshi et al. 2003). In the first reported study of 10 pregnant women and 12 non-pregnant controls, kisspeptin levels increased by 940 -fold in the first trimester and further increased to some $\sim 7000$-fold higher in the third trimester. Circulating kisspeptin levels fell again 5 days post delivery to comparable concentrations prior to pregnancy, implicating a placental source of the peptide. In support of a placental origin, plasma kisspeptin levels are increased in patients with gestational trophoblastic neoplasia and fall during and after treatment with chemotherapy (Dhillo et al. 2006). The circulating levels of kisspeptin are considerably higher than the levels of kisspeptin achieved after exogenous administration, which have been shown to potently stimulate LH (Dhillo et al. 2006). However, LH is not elevated in pregnancy. There are several possible explanations for this apparent discrepancy. For example, the KISS1R receptor in GNRH1 neurons may be desensitized as has been demonstrated in rhesus monkeys (Plant \& Ramaswamy 2009). Alternatively, other factors in pregnancy such as elevated progesterone prevent the GNRH1 neurone from responding to kisspeptin. In addition, there may be species differences in responses, as for example, in the rodent, despite suppression of $\mathrm{LH}$ levels during pregnancy, $\mathrm{LH}$ responses to high $(1 \mathrm{nmol})$ doses of kisspeptin were preserved during gestation (Roa et al. 2006). Moreover, significant $\mathrm{LH}$ responses were observed after central injection of doses as low as 0.1 pmol, suggesting preserved (if not enhanced) sensitivity to kisspeptin during gestation (Roa et al. 2006). Finally, it remains possible that the kisspeptin immunoreactivity measured in pregnancy plasma is not in fact kisspeptin but a cross-reacting peptide/s. Thus, the physiological role of circulating kisspeptin during pregnancy remains uncertain.

Kisspeptin has a prime location at the foeto-maternal interface, being abundant in the syncytiotrophoblast of the both normal human placenta (Bilban et al. 2004) and in molar pregnancies (Janneau et al. 2002). The outer syncytiotrophoblasts lie adjacent to blood vessels allowing easy passage of kisspeptin into the maternal blood (Fig. 1). KISS1R has been identified in both the villous and invasive extravillous human cytotrophoblasts (Janneau et al. 2002, Bilban et al. 2004). Intriguingly, levels of expression of both KISS1 and KISS1R mRNA are higher in first trimester placentae than in term placentae (Bilban et al. 2004), apparently contrasting with higher circulating kisspeptin levels reported during pregnancy (Horikoshi et al. 2003). Although the human and rat differ in regard to length of gestation and placental structure, the spatial and temporal expression of KISS1 and KISS1R are similar. KISS1 mRNA is expressed in the trophoblast giant cells of the rodent placenta (Terao et al. 2004), which are responsible for early invasion as they invade the spiral arteries and replace the endovasculature. These cells are thus considered as having the same functional phenotype as the human extravillous trophoblasts. As in the human, levels of KISS1 and its receptor gradually decline during placental maturation and are not detectable at embryonic (e) day 18.5 (Terao et al. 2004).

The finding of the highest expression levels of KISS1 and KISS1R mRNAs in trophoblast cells during the first trimester in humans and at e12.5 in rodents coincides with the time of peak trophoblast invasion when regulation of this process is of critical importance. 




Figure 1 Schematic demonstrating trophoblast invasion of the maternal blood vessels. Location of kisspeptin and its receptor at the foeto-maternal interface. Figure demonstrates outer syncytiotrophoblasts (ST) lying adjacent to blood vessels allowing easy passage of kisspeptin into maternal blood. KISS1 is expressed in ST (Bilban et al. 2004), while both KISS1 and KISS1R have been identified in both villous and invasive cytotrophoblasts (CT). EC, endothelial cell; SMC, smooth muscle cell.
In vitro, KP10 inhibits the migration and invasion of trophoblast cells (Bilban et al. 2004) and thus it is postulated that kisspeptin plays a key role in restraining trophoblast invasion and regulating implantation and subsequent development. To investigate this hypothesis, circulating levels of kisspeptin have been measured in plasma and serum from women with pregnancies associated with poor placentation. A recent study on a small number of subjects has reported that circulating levels of kisspeptin measured early in pregnancy (between 8 and 14 weeks gestation) were lower in women who later had small for gestational age neonates (Smets et al. 2008). Likewise, lower kisspeptin levels were found in early second trimester $(\sim 16$-week gestation) serum samples from women who subsequently developed pre-eclampsia and/or delivered offspring with intrauterine growth retardation (RA Armstrong, RM Reynolds, R Leask, CH Shearing, AA Calder \& SC Riley, 2008, personal communication). These findings appear to be contrary to a role of kisspeptin in inhibiting invasion. One hypothesis to explain the findings of lower circulating kisspeptin levels in these pregnancies, where reduced invasive capacity would be expected, is that low expression of kisspeptin within the placenta signals low invasive capacity (Smets et al. 2008). Alternatively, development of smaller, less invasive placentas occur first and these produce less kisspeptin. However, another study reported higher KISS1 mRNA and protein, in association lower MMP9 mRNA and protein expression in trophoblasts from women with pre-eclampsia compared with controls and an inverse correlation of KISS1 mRNA expression levels with birth weight (Qiao et al. 2005; Fig. 2). To date, all data regarding circulating kisspeptin, KISS1 expression and pre-eclampsia are correlative and so whether altered kisspeptin levels are a cause or consequence of the disease cannot be determined from these studies. A possible role for kisspeptin in the prevention of ectopic pregnancy has also been speculated upon following the finding of Kiss1 mRNA in mouse fallopian tube (Gaytan et al. 2007), and a potential role in parturition suggested (Torricelli et al. 2008), but clearly more studies are required to test these hypotheses.

\section{Cellular and molecular mechanisms of kisspeptin actions in the placenta}

The mechanisms by which kisspeptin may regulate invasion of the trophoblast into the decidua have not been studied in detail (Bilban et al. 2004) but are likely to involve processes that are emerging in other tissues, such as in tumour biology. For example, kisspeptin has been shown to inhibit MMP expression and activity in vitro (Yan et al. 2001, Yoshioka et al. 2008), and MMPs are critically involved in events taking place at the cell-extracellular membrane interface such as cell division, migration and morphogenesis and ultimately regulate cell behaviour (Mott \& Werb 2004). There are striking similarities between the behaviour of invasive placental cells and of invasive cancer cells. Angiogenesis, the formation of new blood vessels from pre-existing vascular beds, is a common feature of both implantation and cancer spread (Murray \& Lessey 1999) and is of vital importance in establishing the placenta. Kisspeptin and KISS1R expression have been reported in human aorta, coronary artery and umbilical vein and kisspeptin acts as a vasoconstrictor (a crucial phase in angiogenesis) in isolated coronary arteries (Mead et al. 2007a), suggesting a role in the vascular system. A potential angiostatic effect of kisspeptin may also explain, at least in part, the anti-metastatic potential of this peptide given that angiogenesis is intimately involved in this process. Indeed, a very recent gene expression profiling study has emerged to support this hypothesis. In metastatic brain tumours, there was upregulation of genes involved in angiogenesis (vascular endothelial growth factor and placental growth factor), cell adhesion and migration (including integrins, and extracellular matrices collagen and laminin) and marked downregulation of genes involved in apoptosis, neuroprotection and suppression of angiogenesis (including KISS1; Zohrabian et al. 2007). Detailed in vitro and in vivo studies to investigate the potential angiostatic effects and to determine the molecular mechanisms underpinning such effects of kisspeptin are required. 


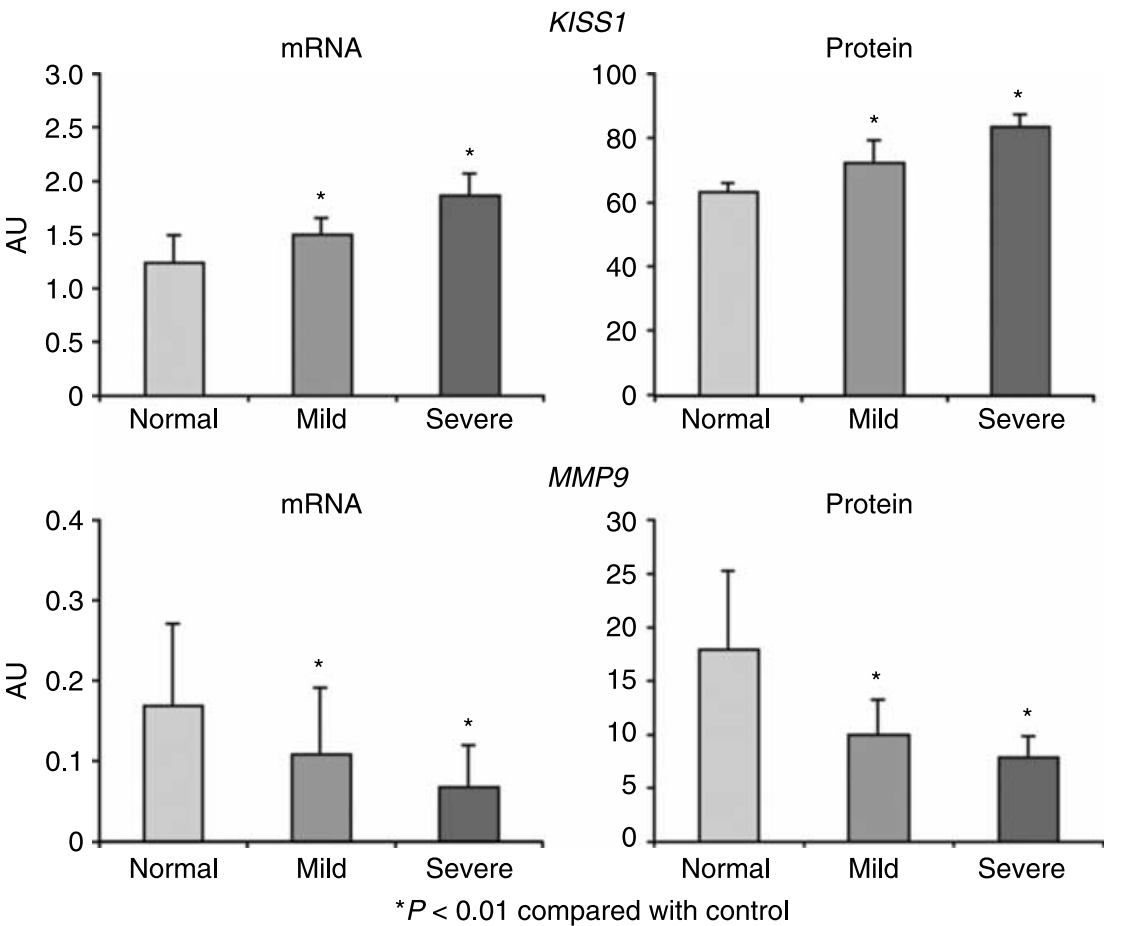

Figure 2 Expression of KISS1 and MMP9 mRNA in trophoblasts from patients with pre-eclampsia and uncomplicated term pregnancies. mRNA and protein measured by RT-PCR and western blot analyses in trophoblasts from 40 patients with pre-eclampsia (mild $(n=15)$; severe $(n=25)$ and 20 cases of term pregnancy (normal)). Figure demonstrates higher KISS1 mRNA and protein, in association lower MMPg mRNA and protein expression in trophoblasts from women with pre-eclampsia. ${ }^{*} P<0.01$ compared with control. Data redrawn from Qiao et al. (2005).

\section{Facts and speculation}

Interestingly, species-specific differences may exist in the importance of the kisspeptin/KISS1R system because, in Kiss $1 r$-knockout mice, males and females were incapable of reproducing when paired with fertile littermates (Funes et al. 2003) whereas successful pregnancies have been reported in human females carrying a KISS1R mutation (Seminara et al. 2003). Of note, the knockout mice have null mutations whereas human mutations are mainly non-sense mutations. Indeed, the physiological relevance of kisspeptin actions in human placental function is challenged by a lack of gross abnormalities in placental formation and/or function in humans and mice carrying null mutations in the Kiss1r gene (Seminara et al. 2003, Pallais et al. 2006). Nevertheless, this does not exclude a role for kisspeptin in the fine tuning of aspects of placental function and physiology. A potential role that KISS1R activation may have in regulating maternal physiology during pregnancy and the postpartum period was provided by evaluating pregnancy outcomes in a female patient bearing the homozygote leucine to serine mutation at amino acid 148 (L148S) within the third intracellular loop of KISS1R (Pallais et al. 2006). All patients carrying homozygous or compound heterozygous mutations in Kiss $1 r$ are living proof of their ability to establish functioning placentas during early gestation. A female homozygote for L148S had a normal vaginal delivery of a healthy child of a normal birth weight, after induction of ovulation, demonstrating that KISS1R signalling in the mother is not critical for placental function and uterine contraction (as suggested by an earlier study in rodents whereby oxytocin production was stimulated by kisspeptin administration (Kotani et al. 2001)). In addition, the ability of the patient with a KISS1R mutation to breastfeed suggests that KISS1R is not critical for lactation (Pallais et al. 2006). Other putative, but little tested, roles for kisspeptin in pregnancy have included a role in aldosterone production and fluid balance (Nakamura et al. 2007). Kisspeptin is also thought to have a central role in the metabolic regulation of reproductive function (Tena-Sempere 2006). Mounting evidence now supports the hypothesis that peripheral, adipocyte-derived leptin modulates the functioning of the reproductive axis, at least in part, via regulation of the kisspeptin/KISS1R system. To date, this role for kisspeptin has principally been explored in relation to puberty but it may also be important in metabolic regulation during pregnancy. Finally, whether kisspeptin functions to downregulate the hypothalamic-pituitarygonadal axis in human pregnancy is not known.

Measurements of circulating kisspeptin levels during pregnancy should be interpreted with caution. In the published studies of kisspeptin in pregnancy, there are significantly different concentrations of circulating kisspeptin (Horikoshi et al. 2003, Dhillo et al. 2006) reported, which may, in part, be attributable to differences in pre-analytical variables, such as collection tube type, processing times, and storage conditions (Ramachandran et al. 2008), but may also reflect problems and/or lack of specificity of different assays used. For example, of the published data in human 
pregnancy, the assays used include an in-house two-site enzyme immunoassay in which the authors confirmed the presence of metastin immunoreactivity by detection of a single peak for metastin on reverse phase HPLC (Horikoshi et al. 2003). Others have used RIAs although the antibodies and methods used differ including both an in-house assay (antibody sourced from Bachem, UK, Merseyside, UK; Dhillo et al. 2006) and a commercially available RIA from Phoenix Pharmaceuticals, Inc. (Blemont, CA, USA; Smets et al. 2008). To date, there are no studies reporting levels of kisspeptin in rodent, or other species, pregnancies. Indeed, most of the data gathered on kisspeptin and placental function are based on correlations of changes in gene expression during pregnancy and immunocytochemical and immunoassay of undefined specificity. The conclusions that kisspeptin/ KISS1R may not play a significant role in implantation and pregnancy derive from successful pregnancy after induction of ovulation in women with KISS1R mutations. However, since kisspeptin is proposed to have a restraining influence on excessive or premature implantation, the phenotype may not be obvious and excessive kisspeptin may be more likely to cause a clear pathological phenotype.

\section{Conclusions}

Since the discovery of kisspeptin in 1996, there has been a rapidly developing field unravelling the potential physiological roles of this peptide. There remain many unanswered questions concerning its function in pregnancy. Kisspeptins do appear to be regulators of invasion both in pathological conditions (tumours) and also in physiological situations including trophoblast invasion in pregnancy. However, the significance of the dramatic rise in circulating levels of kisspeptin during pregnancy remains unknown (Horikoshi et al. 2003). It has been suggested that measurement of circulating levels may be useful as a marker for gestational trophoblastic neoplasia (Dhillo et al. 2006). Further studies are also required to see whether kisspeptin levels measured in pregnancy may be useful as a marker for predicting pregnancies associated with poor placentation such as intrauterine growth retardation or pre-eclampsia. The potential role of kisspeptin in regulating angiogenesis is exciting and may have important implications for physiological processes requiring tightly regulated angiogenesis including menstruation and pregnancy.

\section{Declaration of interest}

The authors declare that there is no conflict of interest that could be perceived as prejudicing the impartiality of this review.

\section{Funding}

J J L was a Jennifer Brown/PiggyBankKids research fellow; A M was supported by a Jennifer Brown/PiggyBankKids summer studentship. A R and R P M were supported by grants from the Medical Research Council.

\section{Acknowledgements}

We thank Dr P Hadoke for his helpful comments on the manuscript.

\section{References}

Becker JA, Mirjolet JF, Bernard J, Burgeon E, Simons MJ, Vassart G, Parmentier M \& Libert F 2005 Activation of GPR54 promotes cell cycle arrest and apoptosis of human tumor cells through a specific transcriptional program not shared by other Gq-coupled receptors. Biochemical and Biophysical Research Communications 326 677-686.

Bilban M, Ghaffari-Tabrizi N, Hintermann E, Bauer S, Molzer S, Zoratti C, Malli R, Sharabi A, Hiden U, Graier W et al. 2004 Kisspeptin-10, a KiSS$1 /$ metastin-derived decapeptide, is a physiological invasion inhibitor of primary human trophoblasts. Journal of Cell Science 117 1319-1328.

Castellano JM, Navarro VM, Fernandez-Fernandez R, Castano JP, Malagon MM, Aguilar E, Dieguez C, Magni P, Pinilla L \& Tena-Sempere M 2006 Ontogeny and mechanisms of action for the stimulatory effect of kisspeptin on gonadotropin-releasing hormone system of the rat. Molecular and Cellular Endocrinology 257-258 75-83.

Colledge WH 2004 GPR54 and puberty. Trends in Endocrinology and Metabolism 15 448-453.

Crown A, Clifton DK \& Steiner RA 2007 Neuropeptide signaling in the integration of metabolism and reproduction. Neuroendocrinology 86 175-182.

d'Anglemont de Tassigny X, Fagg LA, Dixon JP, Day K, Leitch HG, Hendrick AG, Zahn D, Franceschini I, Caraty A, Carlton MB et al. 2007 Hypogonadotropic hypogonadism in mice lacking a functional Kiss1 gene. PNAS 104 10714-10719.

Dhillo WS, Savage P, Murphy KG, Chaudhri OB, Patterson M, Nijher GM, Foggo VM, Dancey GS, Mitchell H, Seckl MJ et al. 2006 Plasma kisspeptin is raised in patients with gestational trophoblastic neoplasia and falls during treatment. American Journal of Physiology. Endocrinology and Metabolism 291 E878-E884.

Funes S, Hedrick JA, Vassileva G, Markowitz L, Abbondanzo S, Golovko A, Yang S, Monsma FJ \& Gustafson EL 2003 The KiSS-1 receptor GPR54 is essential for the development of the murine reproductive system. Biochemical and Biophysical Research Communications 312 1357-1363.

Gaytan M, Castellano JM, Roa J, Sanchez-Criado JE, Tena-Sempere M \& Gaytan F 2007 Expression of KiSS-1 in rat oviduct: possible involvement in prevention of ectopic implantation? Cell and Tissue Research 329 571-579.

Harms JF, Welch DR \& Miele ME 2003 KISS1 metastasis suppression and emergent pathways. Clinical \& Experimental Metastasis 20 11-18.

Hauge-Evans AC, Richardson CC, Milne HM, Christie MR, Persaud SJ \& Jones PM 2006 A role for kisspeptin in islet function. Diabetologia 49 2131-2135.

Hiden U, Bilban M, Knöfler M \& Desoye G 2007 Kisspeptins and the placenta:regulation of trophoblast invasion. Reviews in Endocrine and Metabolic Disorders 8 31-39.

Horikoshi Y, Matsumoto H, Takatsu Y, Ohtaki T, Kitada C, Usuki S \& Fujino M 2003 Dramatic elevation of plasma metastin concentrations in human pregnancy: metastin as a novel placenta-derived hormone in humans. Journal of Clinical Endocrinology and Metabolism 88 914-919.

Janneau JL, Maldonado-Estrada J, Tachdjian G, Miran I, Motte N, Saulnier P, Sabourin JC, Cote JF, Simon B, Frydman R et al. 2002 Transcriptional expression of genes involved in cell invasion and migration by normal and tumoral trophoblast cells. Journal of Clinical Endocrinology and Metabolism 87 5336-5339. 
Kotani M, Detheux M, Vandenbogaerde A, Communi D, Vanderwinden JM, Le PE, Brezillon S, Tyldesley R, Suarez-Huerta N, Vandeput F et al. 2001 The metastasis suppressor gene KiSS-1 encodes kisspeptins, the natural ligands of the orphan G protein-coupled receptor GPR54. Journal of Biological Chemistry 276 34631-34636.

Lanfranco F, Gromoll J, von ES, Herding EM, Nieschlag E \& Simoni M 2005 Role of sequence variations of the $\mathrm{GnRH}$ receptor and $\mathrm{G}$ protein-coupled receptor 54 gene in male idiopathic hypogonadotropic hypogonadism. European Journal of Endocrinology 153 845-852.

Lapatto R, Pallais JC, Zhang D, Chan YM, Mahan A, Cerrato F, Le WW, Hoffman GE \& Seminara SB 2007 Kiss1 - / - mice exhibit more variable hypogonadism than Gpr54-/- mice. Endocrinology 148 4927-4936.

Lee JH \& Welch DR 1997 Suppression of metastasis in human breast carcinoma MDA-MB-435 cells after transfection with the metastasis suppressor gene, KiSS-1. Cancer Research 57 2384-2387.

Lee JH, Miele ME, Hicks DJ, Phillips KK, Trent JM, Weissman BE \& Welch DR 1996 KiSS-1, a novel human malignant melanoma metastasissuppressor gene. Journal of the National Cancer Institute 88 1731-1737.

Lee DK, Nguyen T, O'Neill GP, Cheng R, Liu Y, Howard AD, Coulombe N, Tan CP, Tang-Nguyen AT, George SR et al. 1999 Discovery of a receptor related to the galanin receptors. FEBS Letters 446 103-107.

Mead EJ, Maguire JJ, Kuc RE \& Davenport AP 2007a Kisspeptins are novel potent vasoconstrictors in humans, with a discrete localization of their receptor, G protein-coupled receptor 54, to atherosclerosis-prone vessels. Endocrinology 148 140-147.

Mead EJ, Maguire JJ, Kuc RE \& Davenport AP 2007b Kisspeptins: a multifunctional peptide system with a role in reproduction, cancer and the cardiovascular system. British Journal of Pharmacology 151 1143-1153.

Mott JD \& Werb Z 2004 Regulation of matrix biology by matrix metalloproteinases. Current Opinion in Cell Biology 16 558-564.

Muir Al, Chamberlain L, Elshourbagy NA, Michalovich D, Moore DJ, Calamari A, Szekeres PG, Sarau HM, Chambers JK, Murdock P et al. 2001 AXOR12, a novel human G protein-coupled receptor, activated by the peptide KiSS-1. Journal of Biological Chemistry 276 28969-28975.

Murray MJ \& Lessey BA 1999 Embryo implantation and tumor metastasis: common pathways of invasion and angiogenesis. Seminars in Reproductive Endocrinology 17 275-290.

Nakamura Y, Aoki S, Xing Y, Sasano H \& Rainey WE 2007 Metastin stimulates aldosterone synthesis in human adrenal cells. Reproductive Sciences 14 836-845.

Ohtaki T, Shintani Y, Honda S, Matsumoto H, Hori A, Kanehashi K, Terao Y, Kumano S, Takatsu Y, Masuda Y et al. 2001 Metastasis suppressor gene KiSS-1 encodes peptide ligand of a G-protein-coupled receptor. Nature 411 613-617.

Pallais JC, Bo-Abbas Y, Pitteloud N, Crowley WF Jr \& Seminara SB 2006 Neuroendocrine, gonadal, placental, and obstetric phenotypes in patients with $\mathrm{IHH}$ and mutations in the G-protein coupled receptor, GPR54. Molecular and Cellular Endocrinology 254-255 70-77.

Plant TM \& Ramaswamy S 2009 Kisspeptin and the regulation of the hypothalamic-pituitary-gonadal axis in the rhesus monkey (Macaca mulatta). Peptides 30 67-75.

Qiao C, Wang CH, Shang T \& Lin QD 2005 Clinical significance of KiSS-1 and matrix metalloproteinase- 9 expression in trophoblasts of women with preeclampsia and their relation to perinatal outcome of neonates. Zhonghua Fu Chan Ke Za Zhi 40 585-590.
Ramachandran R, Patterson M, Murphy KG, Dhillo WS, Patel S, Kazarian A, Ghatei MA \& Bloom SR 2008 Preanalytical factors affecting RIA measurement of plasma kisspeptin. Clinical Chemistry 54 615-617.

Roa J, Vigo J, Castellano JM, Navarro VM, Fernández-Fernández R, Casanueva FF, Dieguez C, Aguilar E, Pinilla L \& Tena-Sempere M 2006 Hypothalamic expression of KiSS-1 system and gonadotropin-releasing effects of kisspeptin in different reproductive states of the female rat. Endocrinology 147 2864-2878.

Roa J, Aguilar E, Dieguez C, Pinilla L \& Tena-Sempere M 2008 New frontiers in kisspeptin/GPR54 physiology as fundamental gatekeepers of reproductive function. Frontiers in Neuroendocrinology 29 48-69.

de Roux N, Genin E, Carel JC, Matsuda F, Chaussain JL \& Milgrom E 2003 Hypogonadotropic hypogonadism due to loss of function of the KiSS1derived peptide receptor GPR54. PNAS 100 10972-10976.

Seminara SB, Messager S, Chatzidaki EE, Thresher RR, Acierno JS Jr, Shagoury JK, Bo-Abbas Y, Kuohung W, Schwinof KM, Hendrick AG et al. 2003 The GPR54 gene as a regulator of puberty. New England Journal of Medicine 349 1614-1627.

Semple RK, Achermann JC, Ellery J, Farooqi IS, Karet FE, Stanhope RG, O'Rahilly S \& Aparicio SA 2005 Two novel missense mutations in g protein-coupled receptor 54 in a patient with hypogonadotropic hypogonadism. Journal of Clinical Endocrinology and Metabolism 90 1849-1855.

Smets EM, Deurloo KL, Go AT, van Vugt JM, Blankenstein MA \& Oudejans CB 2008 Decreased plasma levels of metastin in early pregnancy are associated with small for gestational age neonates. Prenatal Diagnosis 28 299-303.

Teles MG, Bianco SD, Brito VN, Trarbach EB, Kuohung W, Xu S, Seminara SB, Mendonca BB, Kaiser UB \& Latronico AC 2008 A GPR54-activating mutation in a patient with central precocious puberty. New England Journal of Medicine 358 709-715.

Tena-Sempere $\mathbf{M} 2006$ KiSS-1 and reproduction: focus on its role in the metabolic regulation of fertility. Neuroendocrinology 83 275-281.

Terao Y, Kumano S, Takatsu Y, Hattori M, Nishimura A, Ohtaki T \& Shintani Y 2004 Expression of KiSS-1, a metastasis suppressor gene, in trophoblast giant cells of the rat placenta. Biochimica et Biophysica Acta 1678 102-110.

Torricelli M, Galleri L, Voltolini C, Biliotti G, Florio P, De BM \& Petraglia F 2008 Changes of placental Kiss-1 mRNA expression and maternal/cord kisspeptin levels at preterm delivery. Reproductive Sciences 15 779-784.

Yan C, Wang H \& Boyd DD 2001 KiSS-1 represses 92-kDa type IV collagenase expression by down-regulating NF-kappa B binding to the promoter as a consequence of Ikappa Balpha -induced block of p65/p50 nuclear translocation. Journal of Biological Chemistry 276 1164-1172.

Yoshioka K, Ohno Y, Horiguchi Y, Ozu C, Namiki K \& Tachibana M 2008 Effects of a KiSS-1 peptide, a metastasis suppressor gene, on the invasive ability of renal cell carcinoma cells through a modulation of a matrix metalloproteinase 2 expression. Life Sciences 83 332-338.

Zohrabian VM, Nandu H, Gulati N, Khitrov G, Zhao C, Mohan A, Demattia J, Braun A, Das K, Murali R et al. 2007 Gene expression profiling of metastatic brain cancer. Oncology Reports 18 321-328.

Received 27 January 2009

First decision 2 March 2009

Accepted 31 March 2009 